\title{
Residenciais de idosos durante a crise do COVID-19: a gestão SOBRAMFA, um modelo eficaz
}

\section{Nursing homes during the pandemic COVID-19 crisis: SOBRAMFA strategies, an efficient model}

(D) Pablo González Blasco ${ }^{1}$, (DMarcelo Rozenfeld Levites ${ }^{1}$, (DGraziela Moreto ${ }^{1}$, DMarco Aurelio Janaudis $^{1}$, Maria Auxiliadora Craice De Benedetto ${ }^{1}$

\section{A situação: uma dupla ameaça}

A atual pandemia pelo COVID-19 nos faz viver tempos difíceis e inéditos. ${ }^{1}$ Os esforços de todos os profissionais de saúde, cada um nas suas competências, são essenciais. Enquanto pesquisadores e cientistas se debatem procurando recursos terapêuticos eficazes, aqueles que estão na linha de frente devotam seus melhores esforços no cuidado clinico dos pacientes afetados. ${ }^{2}$

A cada dia que passa mostra-se imprescindível o cuidado da própria equipe de saúde. Não apenas o cuidado físico (para o qual se tomam todas as providências possíveis em cada caso) mas também da saúde mental. Um elemento da equipe de saúde desanimado, pessimista, sem perspectiva é também um fator de crise, provoca insegurança nos pacientes e nas famílias -mais ainda da que Ihes chega habitualmente da mídia - e nada ajuda na equipe de saúde. Torna-se preciso levantar o moral dos que lidam diariamente com esta ameaça de proporções antes nunca vistas.

\section{A Gestão Prioritária: proporcionar uma perspectiva real e objetiva do próprio cenário}

${ }^{1}$ SOBRAMFA - Educação Médica e Humanismo

\section{Correspondência}

Pablo González Blasco

E-mail: pablogb@sobramfa.com.br

www.sobramfa.com.br

Recebido: 23 Junho 2020

Aceito: 23 Junho 2020

\section{Como citar}

Blasco PG, Levites MR, Moreto G, Janaudis MA, De Benedetto MAC. Residenciais de idosos durante a crise do COVID-19: a gestão SOBRAMFA, um modelo eficaz. Acta Fisiatr. 2020;27(1):1-3.

DOI: 10.11606/issn.2317-0190.v27i1a173136

\section{(c) (i) (5) (2)}

(c) 2020 by Acta Fisiátrica

Este trabalho está licenciado com uma licença

Creative Commons - Atribuição 4.0 Internacional que se vivencia no próprio cenário, apoiar a equipe de saúde a todo momento, assim como aos pacientes e famílias é a ajuda principal e mais importante que a gestão da crise requer.

Cabe aqui dar um exemplo assistencial que ilustra esse modo de agir. A SOBRAMFA ${ }^{5}$ coordena os cuidados de vários residências de idosos, com mais de 650 hóspedes no total. Objetividade e realismo implica tabelar diariamente a evolução dos pacientes -aqueles que precisaram de serem hospitalizados, os óbitos, os isolamentos no próprio residencial e, muito importante, as altas dos que saíram do isolamento. A Figura 1 mostra o acompanhamento desse cenário ao longo de 80 dias de pandemia.

Não se trata de elaborar um estúdio epidemiológico do comportamento da pandemia, nem de estabelecer as bases de protocolos terapêuticos, aspectos que correspondem diretamente aos investigadores e à saúde coletiva. Trata-se de mostrar uma foto da realidade diária que se vivencia neste cenário dos Residenciais de Idosos, e da efetividade das medidas preventivas tomadas pela nossa equipe.

\section{As medidas tomadas que fazem a diferença}

Como a epidemia chegou no Brasil três semanas após os países Europeus e os Estados Unidos, estudamos as ações e os Reports feitos nestes países especificamente nos residenciais de idosos. Além de todos os cuidados no fechamento da casa para visitas, a utilização do equipamentos de proteção individual e treinamento da equipe de como utiliza-lo, um importante aprendizado foi a realização de testagem periódica em todos os pacientes e funcionários independente dos sintomas.

Experiências de locais que aguardaram os sinais clínicos para tomarem ações como isolamento na casa, tratamento ou encaminhamento para hospitais tiveram resultados piores com mais pacientes contaminados, adoecidos e falecidos. ${ }^{6-9}$ 


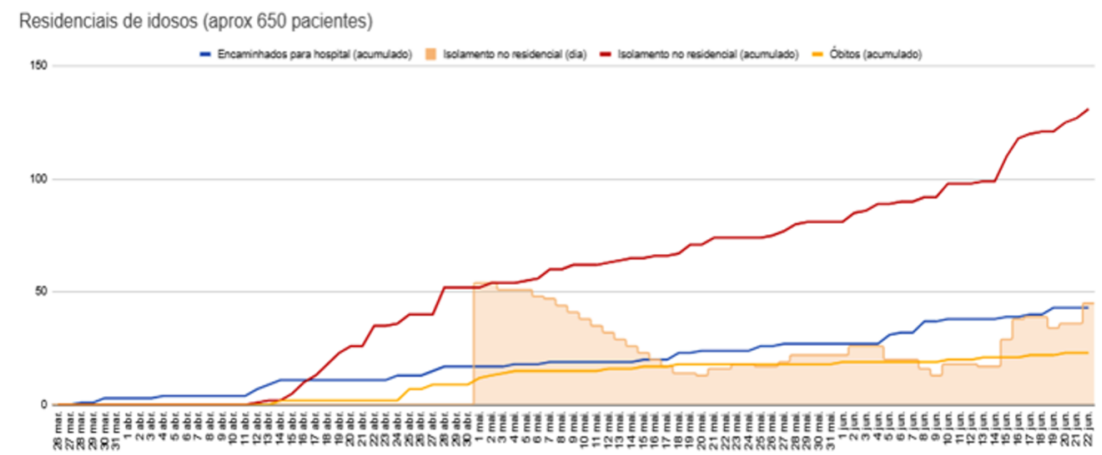

Figura 1. Residenciais de idosos (650 hóspedes) - seguimento em 90 dias

Deste modo, as ações que a nossa equipe praticou são as seguintes:

- O fechamento precoce dos residenciais à visitação: a partir do dia 20 de Março, os hóspedes residentes permaneceram isolados de toda e qualquer visita presencial dos familiares. $O$ único contato dos hospedes tem sido com os profissionais de saúde (médicos e equipe de enfermagem), que atuaram convenientemente protegidos conforme os protocolos adotados globalmente.

- Os hospedes - mesmo os assintomáticos - foram testados para o COVID-19, o que permitia com os resultados isolar os positivos, não permitindo contato com o restante da comunidade.

- Manter diariamente a unidade e o foco da equipe de saúde, com orientação precisa em cada caso, sabendo gerenciar as incertezas normais neste momento. A crise afeta - como já comentado - a própria equipe de saúde que sente-se insegura perante uma ameaça desconhecida. É função do médico inspirar serenidade e profissionalismo para garantir a eficiência. Conversar individualmente com cada uma dos auxiliares e enfermeiras ajudaram a tirar dúvidas e permitir o trabalho equilibrado e sereno de cada um dos membros do time de cuidado dos residenciais

- Comunicação personalizada com as famílias: o isolamento familiar dos hóspedes é desafio enorme com o qual temos de lidar diariamente. Não basta "blindar" o residencial à visitação, é preciso explicar, dar notícias às famílias, esclarecer as dúvidas, mostrar os motivos de todas estas medidas e, de modo particular, nas famílias de pacientes graves que tiveram de ser encaminhados ao hospital, facilitando o contato com os médicos que tiveram de tomar conta dos hóspedes quando hospitalizados.
- Elaboração de material científico e de divulgação. A publicação das nossas experiencias em revistas nacionais ${ }^{10}$ e internacionais, ${ }^{11,12}$ assim como a elaboração de vídeos explicativos ${ }^{13}$ tornaram nossas ações transparentes e disponíveis para a comunidade científica e assistencial que quiseram aproveitá-las. 0 envio dos gráficos de acompanhamento (como o apresentado na Figura 1) foram também disponibilizados diariamente para as equipes de saúde, para os gestores e para a comunidade científica.

\section{O valor agregado na gestão de resultados: uma apologia da comunicação}

É fácil perceber na Figura 1 o valor agregado decorrente dos resultados e das medidas tomadas ao longo destes 3 meses. Dos 650 hóspedes, apenas 6,6\% (43) precisaram ser encaminhados ao hospital. Os falecimentos (a maioria estavam no hospital) foram $23(3,5 \%)$. Chegaram a ser isolados 131 (20\%) pacientes nos próprios residências, sendo que neste momento 45 permanecem em isolamento, estando os restantes recuperados. Os números são alentadores, sobre tudo levando-se em consideração que se trata de população de alta média etária e de risco.

A explicação para esta gestão que consideramos de excelência vem dada pela presença diária e constante da equipe médica da SOBRAMFA, incluídos finais de semana e feriados. É sabido que o setor de atenção ao idoso institucionalizado carece da presença real e ativa do médico, o que é representado frequentemente por visitas com alguma regularidade para cobrir intercorrências, e muitas ações que se delegam na equipe de enfermagem. Deve-se acrescentar também as habilidades de comunicação própria da nossa gestão médica para coordenar a equipe de enfermagem, e atender as solicitações da família de modo habitual.

A situação de crise que o mundo está vivendo, o comportamento e a resposta dos profissionais revela fragilidades nos modelos vigentes de educação em saúde. Contemplamos heroísmo aliado a insegurança, e mesmo imprudência. Conhecimento deforme onde as evidências são diluídas no meio de informações da mídia e do bombardeio sensacionalista das redes sociais.

A capacidade de comunicação, que nestes momentos seria uma das habilidades mais necessárias, deixa muito a desejar nos profissionais desaúde. Cabe lembrar aquele comentário clássico: "todo sistema está perfeitamente desenhado para produzir os resultados que oferece"..$^{14}$ Não podemos simplesmente reclamar do produto; temos de revisar o processo de fabricação que, certamente, é defeituoso.

Uma reflexão mais aprofundada sobre o processo formativo dos médicos foi já traçada com o sugestivo nome de que a ordem dos fatores sim altera o produto. ${ }^{15}$ Lembrava-se que "Curar algumas vezes, aliviar com frequência, confortar sempre", a clássica afirmação que resume a função do médico, apresenta-se numa ordem que encerra um equívoco educacional importante. O que se pode esperar quando a ordem recomendada para a atuação do médico é curar, aliviar e, em último caso, confortar? O lógico é pensar que se avança do mais importante para o detalhe. Quando não se consegue curar é preciso aliviar; e quando o alívio não é possível, resta providenciar conforto. Proceder nessa sequência, fatalmente apresenta o alivio e o conforto como um prêmio de consolação para o médico que se deparou com uma doença incurável, dolorosa, terminal. $\mathrm{O}$ produto resultante desse processo equívoco - o médico - apresenta deficiências importantes.

Em momentos de crise como os que estamos vivendo, e a cura dista muito de ser algo manejável, o alívio e o conforto - para pacientes e familiares - que se deveria esperar dos profissionais não se exerce, porque não se sabe como fazê-lo. Seria necessário um giro hipocrático-copernicano na educação médica, para evitar esse equívoco que rende importantes deficiências formativas. Enquanto confortar é algo que deve ser feito sempre, pela altíssima prevalência, o curar apresenta uma prevalência muito menor. O processo da educação médica deve contemplar essa proporção para produzir melhores médicos. Médicos que sempre sabem confortar e que, segundo os casos e as moléstias com as que se deparam, também sabem curar quando é possível. Quer dizer, a ordem dos fatores altera o produto. 


\section{Conclusão: gestão eficaz implica presença e profissionalismo}

Não houve nenhuma solução mágica para obter estes resultados. Apenas a presença real e ativa dos médicos da SOBRAMFA, com capacidade de liderar a equipe de saúde, e de comunicar-se com as famílias, os hóspedes e os colegas médicos que eventualmente tiveram de intervir ao longo destas semanas. Uma atitude simples e eficaz que configura um novo modelo de negócio e uma postura de excelência no setor de atendimento ao idoso institucionalizado.

\section{REFERÊNCIAS}

1. Holshue ML, DeBolt C, Lindquist S, Lofy KH, Wiesman J, Bruce $\mathrm{H}$, et al. First Case of 2019 Novel Coronavirus in the United States. N Engl J Med. 2020;382(10):92936. Doi: http://dx.doi.org/10.1056/NEJMoa2001191

2. Centers for Disease Control and Prevention. Symptoms. Coronavirus (COVID-19) [text on the Internet]. Washington: CDC; c2020 [cited 2020 May 13]. Available from: https://www.cdc. gov/coronavirus/2019-ncov/symptoms-testing/ symptoms.html

3. Haffajee RL, Mello MM. Thinking globally, acting locally - the U.S. response to Covid-19. N Engl J Med. 2020;382(22):e75. Doi: https://doi.org/10.1056/ NEJMp2006740
4. Podcast 256 - Anthony Fauci: Talking with patients about COVID-19 [Podcast on the Internet]. Waltham: NEJM. Journal Watch, c2020 [cited 2020 March 10]. Available from: https://podcasts.jwatch.org/ index.php/podcast-256-anthony-fauci-talking-withpatients-about-covid-19/2020/03/10/

5. SOBRAMFA Educação Médica \& Humanismo [homepage on the Internet]. São Paulo: SOBRAMFA; c2020 [citado 2020 Jun 23] Disponivel em: https:// sobramfa.com.br/atuacao-clinica/servicos/ residencial-para-idosos/

6. Arons MM, Hatfield KM, Reddy SC, Kimball A, James A, Jacobs JR, et al. Presymptomatic SARS-CoV-2 infections and transmission in a skilled nursing facility. N Engl J Med. 2020;382(22):2081-90. Doi: https://doi.org/10.1056/NEJMoa2008457

7. McMichael TM, Currie DW, Clark S, Pogosjans S, Kay M, Schwartz NG, et al. Epidemiology of Covid-19 in a long-term care facility in King County, Washington. N Engl J Med. 2020;382(21):2005-11. Doi: https://doi. org/10.1056/NEJMoa2005412

8. McMichael TM, Clark S, Pogosjans S, Kay M, Lewis J, Baer A, et al. COVID-19 in a long-term care Facility - King County, Washington, february 27-march 9, 2020. MMWR Morb Mortal Wkly Rep. 2020;69(12):339-42. Doi: https://doi.org/10.15585/ mmwr.mm6912e1

9. Centers for Disease Control and Prevention Preparing for COVID-19: long-term care facilities, nursing homes [text on the Internet]. Washington: CDC; c2020 [cited 2020 June 25]. Available from: https://www.cdc.gov/coronavirus/2019-ncov/hcp/ long-term-care.html
10. Blasco PG, De Benedetto MAC, Levites MR, Moreto $G$, Janaudis MA. Humanism and medical education in times of COVID-19. Rev Med (São Paulo). 2020;99(2):i-vi. Doi: http://dx.doi.org/10.11606/ issn.1679-9836.v99i2pi-vi

11. Blasco PG, De Benedetto MAC, Levites MR, Moreto G, Janaudis MA. Brazilian family medicine team develops videos: humanism and medical education in times of COVID-19 [homepage on the Internet]. Leawood: Annals of Family Medicine; c2020 [cited 2020 May 5]. Available from: https://medium.com/ case-notes-from-the-covid-19-front-lines/brazilianfamily-medicine-team-develops-videos-humanismand-medical-education-in-times-of-covid-19$67477352 a 69 f$

12. Blasco, PG, De Benedetto MAC. A senior family doctor supporting the health team in times of COVID-19 [text on the Internet]. Toronto: Canadian Family Physician (CFP); c2020 [cited 2020 April 28]. Available from: https://www.cfp.ca/news/2020/04/28/04-28-1

13. Blasco PG. Humanismo médico em tempos de crise [homepage on the Internet]. São Paulo: SOBRAMFA; c2020 [citado 2020 Jun 23]. Disponível em: https:// vimeo.com/showcase/6982727

14. Carr S. Editor's Notebook: a quotation with a life of its own [text on the Internet]. Middleton: Patient Safety \& Quality Healthcare (PSQH); c2008. [cited 2020 June 23]. Available from: https://www.psqh.com/analysis/ editor-s-notebook-a-quotation-with-a-life-of-its-own/

15. Blasco PG. A ordem dos fatores altera o produto. Reflexões sobre educação médica e cuidados paliativos. Educ Med. 2018;19(2):104-14. Doi: https:// doi.org/10.1016/j.edumed.2016.07.010 